\title{
KAJIAN PERTUMBUHAN RESTORASI MANGROVE PADA KAWASAN TAMAN NASIONAL KUTAI KALIMANTAN TIMUR
}

\author{
Asnaenie $^{1}$, Abubakar M. Lahjie ${ }^{2}$, B.D.A.S. Simarangkir ${ }^{2}$, dan Yosep Ruslim² \\ ${ }^{1}$ Program Magister Ilmu Kehutanan, Fakultas Kehutanan \\ Universitas Mulawarman. \\ ${ }^{2}$ Fakultas Kehutanan Universitas Mulawarman. Jl. Ki Hajar Dewantara, Gunung Kelua, \\ Samarinda 75116, Kalimantan Timur, Indonesia.Tel.: +62-541-735089, Fax.: +62-541- \\ 735379. \\ E-Mail: nurulilmi014@gmail.com
}

\begin{abstract}
ABSTRAK
Kajian Pertumbuhan Restorasi Mangrove Pada Kawasan Taman Nasional Kutai Kalimantan Timur. Penelitian ini dilaksanakan di kawasan Taman Nasional Kutai (TNK) Provinsi Kalimantan Timur. Tujuan dari penelitian ini adalah Mengetahui laju tingkat pertumbuhan tanaman pada lahan restorasi mangrove di TNK, Mengetahui hubungan kualitas lahan restorasi dengan laju pertumbuhan tanaman pada lahan restorasi mangrove di TNK, Mengetahui faktor tempat tumbuh yang berpengaruh nyata terhadap laju pertumbuhan. Lokasi penelitian terdiri atas 4 (empat) Stasiun Pengamatan yakni Stasiun Pengamatan I dan II berada di Kota Bontang dan Stasiun Pengamatan III dan IV berada di Desa Sangkima Kabupaten Kutai Timur. Penelitian ini merupakan kombinasi antara penelitian menerangkan (explanatori research) dan penelitian deskriptif (deskriptif research). Penelitian yang bersifat menerangkan adalah penelitian yang menyangkut pengujian hipotesis. Hasil penelitian ini dapat disimpulkan sebagai berikut: Pemilihan lahan restorasi sebaiknya di sesuaikan dengan jenis yang sesuai dengan tempat tumbuh. Laju bertumbuhan tanaman dipengaruhi oleh pemilihan tempat tumbuh dan terlindung dari kuat arus. Dari hasil penelitian di beberapa stasiun, kegiatan restorasi yang di lakukan di TNK sebagian tidak sesui dengan jenis tempat tumbuh tanaman.
\end{abstract}

Kata kunci : Pertumbuhan, restorasi, Mangrove.

\begin{abstract}
Study of Mangrove Restoration Growth in the East Kalimantan Kutai National Park Area. This research was conducted in the East Kalimantan Kutai National Park (KNP) area. The purpose of this study was to determine the rate of growth of plants on mangrove restoration land in TNK, to find out the relationship between the quality of restoration land and the growth rate of plants on mangrove restoration land in TNK. The research location consisted of 4 (four) Observation Stations namely Observation Station I II located in Bontang City and Observation Station III - IV in Sangkima Village, East Kutai Regency. This research is a combination of research explaining (explanatory research) and descriptive research (descriptive research). Explanatory research is research that involves testing hypotheses. The results of this study can be summarized as follows: The selection of the restoration area should be adjusted to the type that suits the place to grow. Plant growth rates are influenced by the choice of place to grow and are protected from strong currents. From the results of research at several stations, some of the restoration activities carried out in TNK are not in accordance with the types of plants that grow.
\end{abstract}

Key words : Growth, Restoration, Mangrove.

\section{PENDAHULUAN}

Taman Nasional Kutai (TNK) salah satu kawasan koservasi yang memiliki perwakilan tipe ekosistem mangrove seluas 5. 277,79 ha atau $2.66 \%$ luas total kawasan TNK (Wijaya, 2011). 
Berdasarkan data TNK tahun 2018 luas kawasan mangrove $2.870,57$ ha hutan mangrove pimer dan $1.957,07$ ha hutan mangrove sekunder. Sebagian kawasan TNK telah mengalami deforestasi, seperti yang terjadi di wilayah Kabupaten Kutai Timur dan wilayah Kota Bontang yang mana cenderung disebabkan pembukaan lahan tambak yang luas dan pemukiman penduduk. Fenomena ini menyebabkan penurunan luas hutan mangrove dan kerusakan vegetasi mangrove di beberapa tempat, Buadiarsa dan Rizal (2013). Sriyanto et al. (2005) dalam Setio dan Mukhtar (2005) menyampaikan salah satu bentuk tindakan yang dapat diterapkan pada kawasan yang mengalami perambahan kawasan yaitu yang disebut restorasi, di mana kegiatannya ditekankan pada pemulihan ekosistem melalui revegetasi secara aktif dengan spesies yang semula ada, sehingga mencapai struktur dan komposisi spesies seperti semula.

Menurut data PSSDAL

BAKOSURTANAL tahun 2012 menyebutkan bahwa luas mangrove Indonesia saat ini mencapai $\pm 3.244 .018,45$ ha, dengan mangrove yang paling terluas ada di provinsi Papua yang mencapai $\pm 1.634 .003,45$ ha, kemudian provinsi Kalimantan Timur seluas $\pm 364.254,98$ ha, dimana sebagian besar berada di luar kawasan hutan. Dari data luasan mangrove tersebut sekitar 1,5\% mangrovenya berada di Taman Nasional Kutai. Dari luasan tersebut saat ini banyak mengalami kerusakan terutama pada wilayah yang berdekatan dengan pemukiman penduduk terutama pada dua wilayah yakni Teluk lambok dan wilayah Bontang. Oleh karenanya diperlukan kegiatan pemulihan ekosistemnya kembali agar dapat mengembalikan fungsi-fungsi ekosistem mangrove seperti pada keadaan semula. Mengharmonisasikan perilaku lingkungan sosial dapat dilakukan dengan cara memberikan penyuluhan, pelatihan dan atau menunjukkan contoh-contoh aktivitas yang berwawasan pelestarian lingkungan. Agar langkah kongkrit di atas dapat dilakukan serasi dan selaras serta sejalan berdasarkan kaidah-kaidah konservasi, akuntabilitas kinerja petugas juga perlu dibekali dengan pengetahuan yang dinilai memadai. Kawasan yang telah dirambah oleh masyarakat dilakukan upaya percepatan pemulihan ekosistemnya yang meliputi kegiatan Restorasi dan Rehabilitasi dengan melibatkan seluruh mitra TNK. Restorasi dan Rehabilitasi bertujuan untuk mengembalikan ekosistem TNK, juga dimaksudkan untuk penguasaan kembali kawasan hutan yang dirambah oleh masyarakat. Dari 2010 sampai dengan tahun 2014, telah dilakukan Restorasi dan Rehabilitasi seluas 6.749 hektar. Hal ini berarti kegiatan Restorasi dan Rehabilitasi selama 2010-2014 telah mencapai kurang lebih $15 \%$. TNK bekerjasama dengan berbagai mitra salah satunya Pemerintah Kabupaten Kutai Timur, PT. Pupuk Kaltim, LSM Bikal, PT. NG Bontang dan masyarakat lokal melaksanakan upaya pemulihan ekosistem mangrove dengan menanam tanaman mangrove di daerah Teluk Perancis seluas 350 ha dan 700 ha di daerah Tanjung Limau dan Bontang Kuala. Upaya restorasi/pemulihan ekosistem mangrove ini tujuan utamanya adalah untuk mengembalikan fungsi ekosistem mangrove di TNK dan untuk penguasaan kembali kawasan hutan mangrove, oleh karena itu sangat diperlukan suatu kajian ekologis tentang keberhasil kegiatan restorasi mangrove yang telah dilakukan sehingga diharapkan menjadi suatu rujukan dan referensi pemulihan ekosistem mangrove di TNK khususnya dan pemulihan ekosistem mangrove di Kalimantan Timur pada umumnya. 


\section{METODA PENELITIAN}

\subsection{Tempat dan Waktu}

Penelitian ini dilaksanakan di kawasan Taman Nasional Kutai (TNK) Provinsi Kalimantan Timur. Lokasi penelitian terdiri atas 4 (empat) Stasiun Pengamatan yakni Stasiun Pengamatan I - II berada di Kota Bontang dan Stasiun Pengamatan III - IV berada di Desa Sangkima Kabupaten Kutai Timur. Waktu yang diperlukan dalam penelitian ini selama kurang lebih 3 (tiga) bulan dengan rentang waktu penelitian dimulai pada bulan JuniAgustus 2017.

\subsection{Metode Analisis Data}

Penelitian ini merupakan kombinasi antara penelitian menerangkan (explanatori research) dan penelitian deskriptif (deskriptif research). Penelitian yang bersifat menerangkan adalah penelitian yang menyangkut pengujian hipotesis. Penelitian semacam ini, dalam deskripsinya juga mengandung uraian-uraian, tetapi fokusnya terletak pada analisis hubungan antara variabel. Proses analisis Statistika deskriptif merupakan metode yang berkaitan dengan pengumpulan data sehingga memberikan informasi yang berguna. Upaya penyajian ini dimaksudkan mengungkapkan informasi penting yang terdapat dalam data ke dalam berbentuk yang lebih ringkas dan sederhana yang pada akhirnya mengarah pada keperluan adanya penjelasan dan penafsiran. Statistik deskriptif digunakan untuk analisis bagi variabel-variabel yang dinyatakan dengan sebaran frekuensi, baik secara angka-angka mutlak maupun secara persentasi. Tabel frekuensi yang dibuat berguna untuk mengelompokkan data dalam tabel silang. Tabel silang sebagai metode yang sederhana digunakan untuk menyoroti dan menganalisis hubungan antara dua variabel atau lebih. Analisis Variabel Pertumbuhan Dan Parameter Analisis ragam adalah suatu metode untuk menguraikan keragaman total data kita menjadi komponen-komponen yang mengukur berbagai sumber keragaman (Walpole 1995). Uji F merupakan pengujian secara bersama-sama pengaruh variabel independen terhadap variabel dependen. Uji ini dilakukan dengan membandingkan nilai $\mathrm{F}$ hitung dengan nilai F-tabel. Apabila nilai $\mathrm{F}$ hitung lebih besar dari nilai F-tabel, maka variabel bebas secara bersamasama mempunyai pengaruh yang signifikan terhadap variabel tidak bebas.

\section{HASIL PENELITIAN DAN PEMBAHASAN}

\subsection{Pertumbuhan Diameter Batang (cm)}

1. Pengamatan Stasiun I dan II
Selama 3 (tiga) bulan
pengamatan (lampiran 1) dapat
disusun nilai rata-rata kombinasi
pertumbuhan seperti yang disajikan
pada tabel dibawah ini.


Tabel: Rata-rata pertumbuhan diameter batang $(\mathrm{cm})$

\begin{tabular}{ccrlcccr}
\hline Plot & $\mathbf{N}$ & \multicolumn{1}{c}{$\boldsymbol{x}$} & $\mathbf{S}^{\mathbf{2}}$ & $\mathbf{S}$ & Min & Max & \multicolumn{1}{c}{ CV $(\boldsymbol{\%})$} \\
\hline 1 & 5 & 3.546 & 0.27107 & 0.52065 & 3.17 & 3.87 & 7.6444 \\
2 & 5 & 3.08 & 0.24166 & 0.49159 & 2.87 & 3.43 & 7.8461 \\
3 & 5 & 1.672 & 0.11798 & 0.34349 & 1.51 & 1.83 & 7.0564 \\
4 & 5 & 0.96 & 0.12409 & 0.35227 & 0.77 & 1.07 & 12.9260 \\
\hline Total & $\mathbf{2 0}$ & $\mathbf{2 . 3 1 4 5}$ & $\mathbf{1 . 0 8 5 6 7}$ & $\mathbf{1 . 7 0 8 0 0}$ & $\mathbf{0 . 7 7}$ & $\mathbf{3 . 8 7}$ & $\mathbf{4 6 . 9 0 7 5}$ \\
\hline
\end{tabular}

Keterangan : N = Jumlah Sample, $\bar{x}=$ Rata-Rata Hitung,

$\mathrm{S}^{2}=$ Varians, $\mathrm{S}=$ Standart Deviasi, $\mathrm{CV}=$ Coeffisien Variasi

Berdasarkan hasil pengukuran dapat dikemukakan bahwa diameter batang mengalami pertumbuhan yang baik, pada tabel tersebut menunjukkan bahwa rata-rata pertumbuhan diameter batang pada kisaran 0,77 dan $3,87 \mathrm{~cm}$ selama 3 (tiga) bulan pengamatan.
Menunjukkan perbedaan yang sangat signifikan pada Stasiun I dan II, hal ini di sebabkan karena tanaman pada plot 1 dan 2 merupakan tanaman berdiameter lebih besar dibandingkan dengan tanaman yang berada pada plot 3 dan 4 .

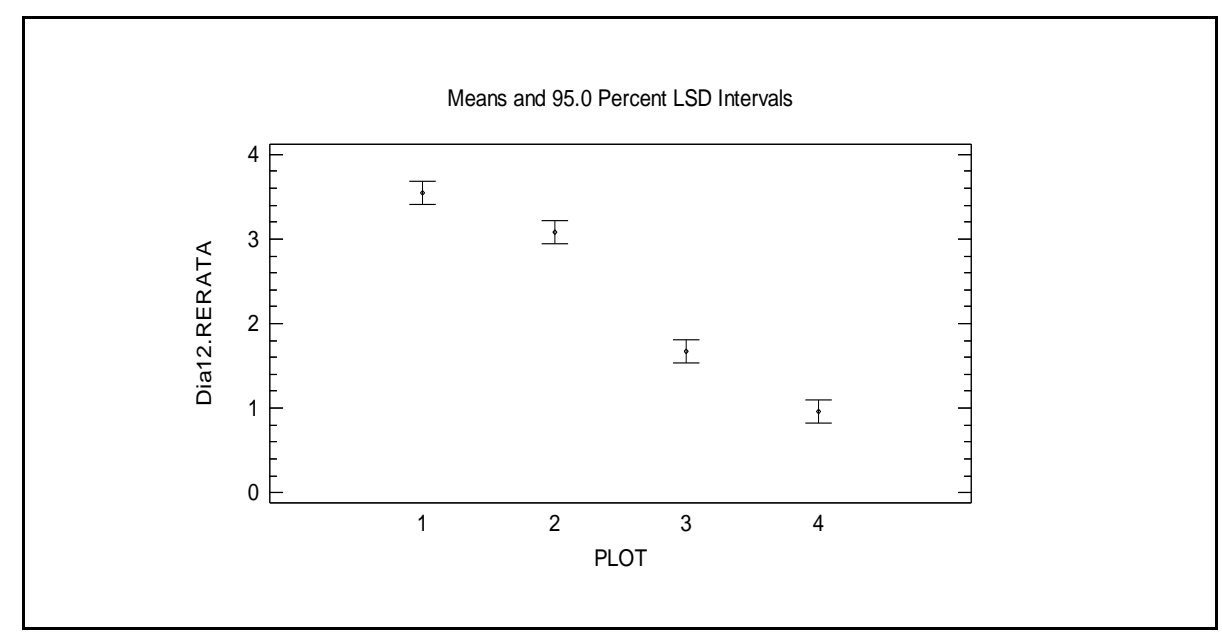

Gambar 1. Pertumbuhan diameter batang (cm) stasiun I dan II

Dibawah ini dapat kita lihat perbedaan yang signifikan antara plot 1 dengan plot yang lain, dengan tanda

Tabel 2. Perbedaan pertumbuhan diameter batang $(\mathrm{cm})$

\begin{tabular}{ccccc}
\hline Plot & Signifikan & Perbedaan & F-Ratio & P-Value \\
\hline $1-2$ & $*$ & 0.466 & $\mathbf{1 7 9 . 9 0}$ & $\mathbf{0 . 0 0 0 0}$ \\
$1-3$ & $*$ & 1.874 & & \\
$1-4$ & $*$ & 2.586 & & \\
$2-3$ & $*$ & 1.408 & & \\
$2-4$ & $*$ & 2.120 & & \\
$3-4$ & $*$ & 0.712 & & \\
\hline
\end{tabular}

bintang (*) menandakan signifikan atau berbeda nyata. 
Dari hasil pengamatan diketahui pertumbuhan diameter batang yang terbaik bila dibanding dengan lokasi penanaman lainnya, diduga karena pada lokasi tersebut merupakan daerah yang sangat cocok untuk tumbuh jenis bakau (R. mucronata) dan akan hidup baik pada kondisi yang agak basah dan lumpur yang agak dalam. Hal ini di dukung hasil uji dari Laboratorium Ilmu Tanah (Lampiran 2), pada Stasiun I terhadap kandungan unsur makro (N, P, K, Ca dan $\mathrm{Mg}$ ) yang lebih tinggi dibandingkan dengan Stasiun II, dimana unsur tersebut sangat di butuhkan untuk pertumbuhan tanaman. Menurut Subroto (2003), unsur hara makro diserap oleh tanaman dalam jumlah cukup banyak, masing-masing berperan di dalam pertumbuhan dan perkembangan tanaman.

\section{Pengamatan Stasiun III dan IV}

Berdasarkan hasil pengamatan pada stasiun selanjutnya diperoleh data pertumbuhan yang tidak terlalu jauh perbedaannya seperti pada tabel berikut.

Tabel 3. Rata-rata pertumbuhan diameter batang $(\mathrm{cm})$

\begin{tabular}{cccccccr}
\hline Plot & N & $\overline{\boldsymbol{x}}$ & $\mathbf{S}^{\mathbf{2}}$ & S & Min & Max & \multicolumn{1}{c}{ CV $(\boldsymbol{\%})$} \\
\hline 5 & 5 & 1.046 & 0.11802 & 0.34354 & 0.87 & 1.20 & 11.283 \\
6 & 5 & 0.908 & 0.26147 & 0.51134 & 0.70 & 1.27 & 28.797 \\
7 & 5 & 0.994 & 0.15693 & 0.39614 & 0.73 & 1.10 & 15.788 \\
8 & 5 & 1.106 & 0.17343 & 0.41645 & 0.83 & 1.27 & 15.681 \\
\hline Total & $\mathbf{2 0}$ & $\mathbf{1 . 0 1 3}$ & $\mathbf{0 . 1 8 5 4 8}$ & $\mathbf{1 . 6 6 7 4 7}$ & $\mathbf{0 . 7 0}$ & $\mathbf{1 . 2 7}$ & $\mathbf{1 8 . 3 0 1}$ \\
\hline
\end{tabular}

Dari hasil pengukuran dapat dikemukakan bahwa diameter batang pada stasiun III mengalami pertumbuhan kurang baik (lampiran 3), pada tabel tersebut menunjukkan bahwa rata-rata pertumbuhan diameter batang pada kisaran 0,70 dan $1,27 \mathrm{~cm}$ selama 3 (tiga) bulan pengamatan. Hal ini di sebabkan ada beberapa tanaman tidak mendapat pertambahan tumbuh, sebagaimana pendapat Hanum (2008), pertumbuhan tanaman yang kekurangan unsur hara $\mathrm{N}$ menjadi kerdil dan lemah pada tahap selanjutnya daun mengering dan akan rontok.

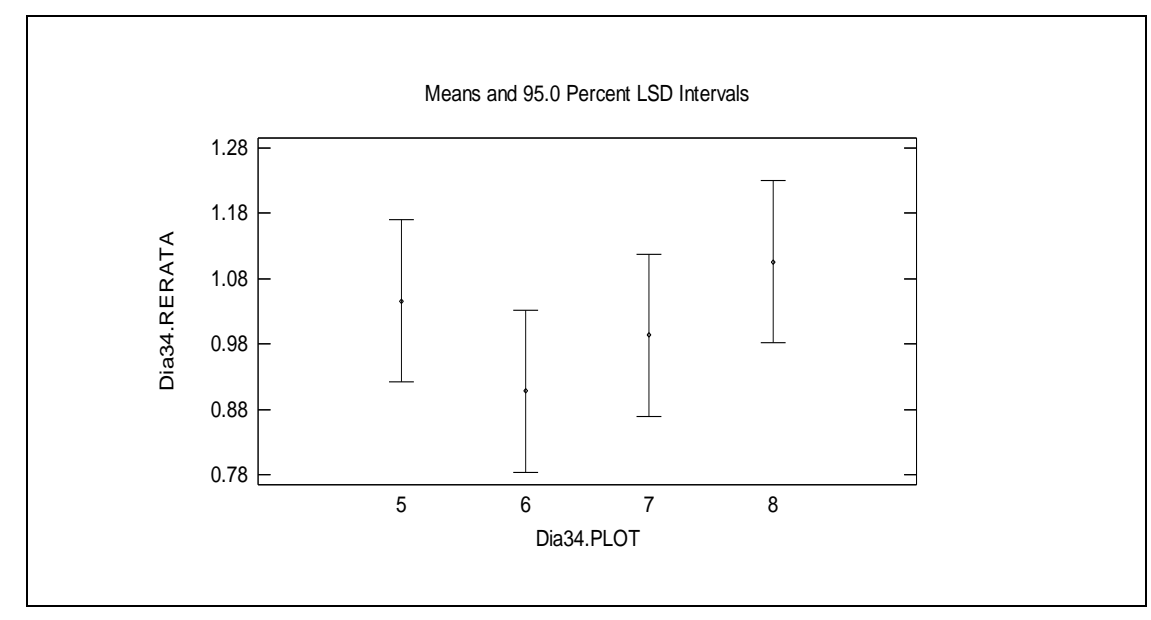

Gambar 2. Pertumbuhan diameter batang (cm) 
Pada gambar diatas diagram pertambahan diameter yang dihasilkan sangat kecil dapat dilihat pula pada tabel dibawah ini dimana data pada plot 5 dan plot lainnya tidak signifikan dan di peroleh tidak nyata pada tanaman, yang dilambangkan dengan $t n$.

Tabel 4. Perbedaan pertumbuhan diameter batang $(\mathrm{cm})$

\begin{tabular}{ccccc}
\hline Plot & Signifikan & Perbedaan & F-Ratio & P-Value \\
\hline $5-6$ & $t n$ & 0.138 & 1.03 & 0.4066 \\
$5-7$ & $t n$ & 0.052 & & \\
$5-8$ & $t n$ & -0.06 & & \\
$6-7$ & $t n$ & -0.086 & & \\
$6-8$ & $t n$ & -0.198 & & \\
$7-8$ & $t n$ & -0.112 & & \\
\hline
\end{tabular}

Menurut $\begin{array}{r}\text { Ruchaemi } \\ \text { tumbuh }\end{array}$
(2013), tempat sangat
merupakan faktor yang sangar
berpengaruh terhadap
pertumbuhan, semakin subur
suatu lahan maka akan semakin
baik pertumbuhan. Hal ini
didasari oleh hasil uji
laboratorium kandungan unsur
$\mathrm{N}$ dan K sangat rendah di
banding stasiun lain. Selain itu
tempat tumbuh yang merupakan

padang lamun adalah lumpur yang mengandung pasir.

\subsection{Pertumbuhan Tinggi Batang $(\mathrm{cm})$}

1. Stasiun I dan II

Selama 3 (tiga) bulan pengamatan (lampiran 4) dapat disusun nilai rata-rata kombinasi pertumbuhan seperti yang disajikan pada tabel dibawah ini.

Tabel 5. Rata-rata pertumbuhan tinggi tanaman $(\mathrm{cm})$

\begin{tabular}{cccccccc}
\hline Plot & $\mathbf{N}$ & $\overline{\boldsymbol{x}}$ & $\mathbf{S}^{\mathbf{2}}$ & $\mathbf{S}$ & $\mathbf{M i n}$ & $\mathbf{M a x}$ & $\mathbf{C V}(\boldsymbol{\%})$ \\
\hline 1 & 5 & 249.50 & 28.8268 & 5.3696 & 213.50 & 277.50 & 11.5538 \\
2 & 5 & 250.832 & 26.0133 & 5.10032 & 224.83 & 288.33 & 10.3708 \\
3 & 5 & 30.598 & 8.108 & 2.84745 & 20.00 & 38.83 & 26.4985 \\
4 & 5 & 36.70 & 10.2226 & 3.1972 & 26.33 & 49.17 & 27.8545 \\
\hline Total & $\mathbf{2 0}$ & $\mathbf{1 4 1 . 9 0 7}$ & $\mathbf{1 1 2 . 6 7 3}$ & $\mathbf{1 0 . 6 1 4 7}$ & $\mathbf{2 0 . 0 0}$ & $\mathbf{2 8 8 . 3 3}$ & $\mathbf{7 9 . 3 9 8 6}$ \\
\hline
\end{tabular}

Berdasarkan hasil pengukuran dapat dikemukakan bahwa pertumbuhan tinggi tanaman mengalami pertumbuhan dengan baik, pada plot 1 dan 2 memiliki pertumbuhan tinggi yang berbeda seperti yang disajikan pada tabel 5. Pada tabel tersebut menunjukkan bahwa pertumbuhan tinggi mencapai 
20,00 dan $288,33 \mathrm{~cm}$ selama 3

dilihat pada gambar dibawah.

(tiga) bulan pengamatan, dapat

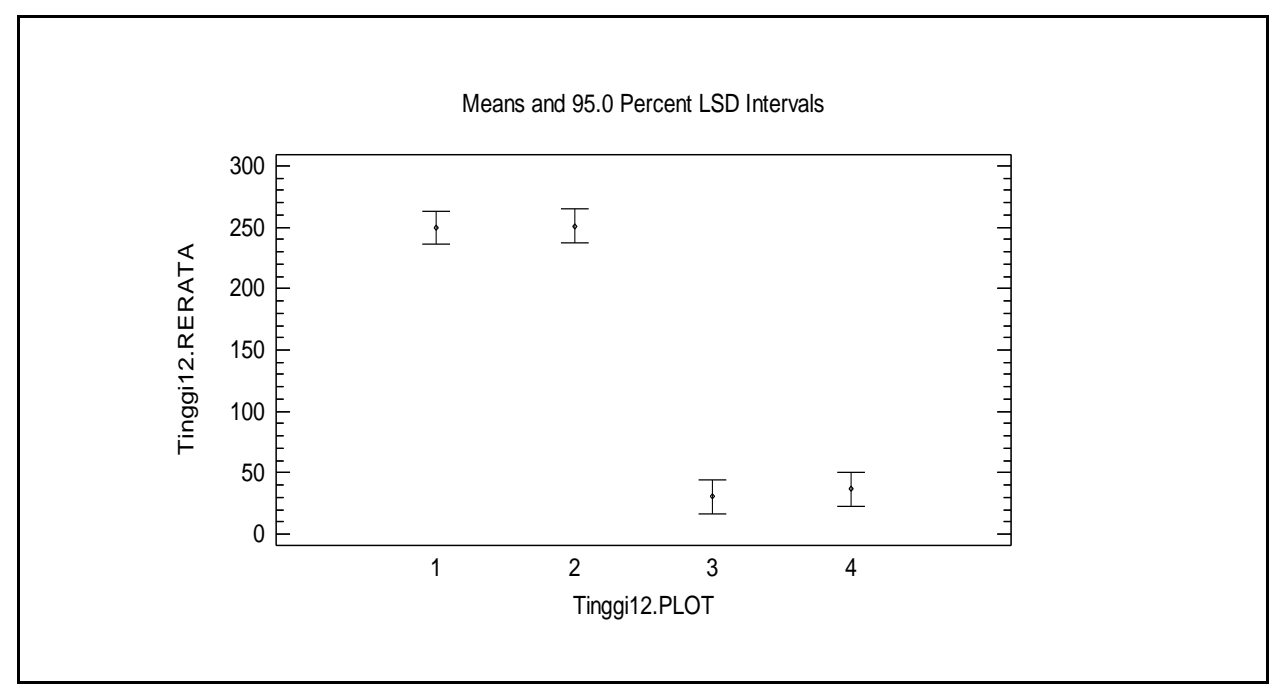

Gambar 3. Pertumbuhan tinggi tanaman (cm)

Tabel 6. Perbedaan pertumbuhan tinggi tanaman $(\mathrm{cm})$

\begin{tabular}{ccccc}
\hline Plot & Signifikan & Perbedaan & F-Ratio & P-Value \\
\hline $1-2$ & tn & -1.332 & 186.34 & 0.0000 \\
$1-3$ & $*$ & 218.902 & & \\
$1-4$ & $*$ & 212.8 & & \\
$2-3$ & $*$ & 220.234 & & \\
$2-4$ & $*$ & 214.132 & & \\
$3-4$ & tn & -6.102 & & \\
\hline
\end{tabular}

Pengamatan yang di lakukan pada stasiun I dan II mengalami pertumbuhan dengan baik, diduga karena faktor lingkungan tempat tumbuhnya sangat baik, sesuai pendapat Kusmana (2002), yang mengatakan bahwa pertumbuhan mangrove sangat tergantung pada faktor-faktor lingkungannya diantaranya fisiologi pantai, iklim, pasang surut, gelombang dan arus, salinitas, oksigen terlarut, tanah,
Seperti dikemukakan oleh Subroto (2003), bahwa kesuburan tanah tergantung kepada kemampuan tanah menyediakan nutrisi/hara, dan kondisi klimaks tanah, untuk mendukung pertumbuhan dan perkembangan tanaman secara optimal hingga tanaman tersebut dapat melakukan proses fisiologi.

\section{Stasiun III dan IV}


Tabel 7. Pertumbuhan tinggi tanaman $(\mathrm{cm})$

\begin{tabular}{|c|c|c|c|c|c|c|c|}
\hline Plot & $\mathbf{N}$ & $\bar{x}$ & $\mathrm{~S}^{2}$ & $\mathbf{S}$ & Min & Max & $\mathrm{CV}(\%)$ \\
\hline 5 & 5 & 59.368 & 19.8495 & 4.4552 & 44.00 & 81.17 & 33.434 \\
\hline 6 & 5 & 49.000 & 7.10155 & 2.6648 & 43.33 & 61.00 & 14.493 \\
\hline 7 & 5 & 48.066 & 5.14982 & 2.2693 & 42.83 & 54.33 & 10.714 \\
\hline 8 & 5 & 60.898 & 11.8992 & 3.4495 & 46.00 & 75.50 & 19.539 \\
\hline Total & 20 & 54.333 & 12.8371 & 12.838 & 42.83 & 81.17 & 23.626 \\
\hline
\end{tabular}

Berdasarkan hasil pengukuran dapat dikemukakan bahwa pertumbuhan tinggi tanaman mengalami pertumbuhan yang tidak seimbang. Pada tabel tersebut menunjukkan bahwa pertumbuhan tinggi mencapai 54,33 dan $81,17 \mathrm{~cm}$ selama 3 (tiga) bulan pengamatan, dapat dilihat pada gambar dibawah.

Tabel 8. Perbedaan pertumbuhan tinggi tanaman $(\mathrm{cm})$

\begin{tabular}{ccccc}
\hline Plot & Signifikan & Perbedaan & F-Ratio & P-Value \\
\hline $5-6$ & th & 10.368 & 1.48 & 0.2572 \\
$5-7$ & tn & 11.302 & & \\
$5-8$ & tn & -1.53 & & \\
$6-7$ & tn & 0.934 & & \\
$6-8$ & tn & -11.898 & & \\
$7-8$ & tn & -12.832 & & \\
\hline
\end{tabular}

Perbedaan pertumbuhan pertumbuhan tidak memberikan pengaruh berpengaruh tidak nyata terhadap yang nyata terhadap pertumbuhan tinggi pertumbuhan tinggi tanaman seperti yang tanaman bakau. Didug karena tempat disajikan pada tabel 7. Hal ini tumbuh merupakan daerah Padang lamun menunjukkan bahwa laju tingkat dan tidak terlindung dari arus yang kuat.

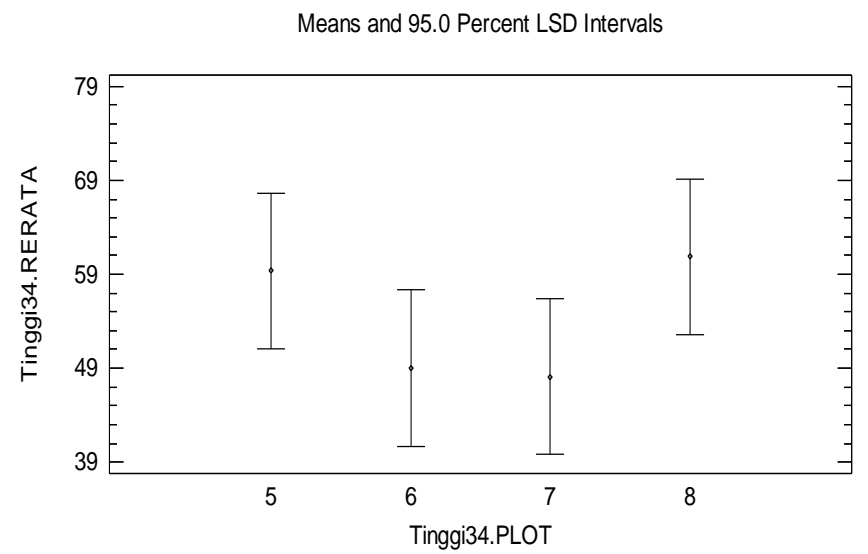

Gambar 4. Pertumbuhan tinggi tanaman 
Pertumbuhan mangrove di berbagai tempat kerap mengalami kegagalan karena tidak memperhatikan kesesuaian spesies dengan tempat tumbuhnya.

\section{KESIMPULAN}

Berdasarkan hasil pembahasan dapat ditarik beberapa kesimpulan sebagai berikut : 1) Pemilihan lahan restorasi sebaiknya di sesuaikan dengan jenis yang sesuai dengan tempat tumbuh. 2) Laju bertumbuhan tanaman dipengaruhi oleh pemilihan tempat tumbuh dan terlindung dari kuat arus. 3)

Dari hasil penelitian di beberapa stasiun, kegiatan restorasi yang di lakukan di TNK sebagian tidak sesui dengan jenis tempat tumbuh tanaman.

\section{DAFTAR PUSTAKA}

$\begin{array}{cr}\text { Anonim 2005. Modul } & \text { Pendidikan } \\ \text { Lingkungan. } & \text { Departemen } \\ \text { Kehutanan. Jakarta } & \end{array}$

Anonim, 1995. Mengenal Taman Nasional Kutai. Departemen Kehutanan Direktorat Jenderal Perlindungan Hutan dan Pelestarian Alam Balai Taman Nasional Kutai. Bontang.

Bratawinata, A.A. 2012. Ekologi Hutan Pesisir. Laboratorium Dendrologi dan Ekologi Hutan. Fakultas Kehutanan Universitas Mulawarman. Samarinda.

Bengen D. G. 2004. Pengenalan dan Pengelolaan Ekosistem Mangrove. Pusat Kajian Sumberdaya Pesisir dan Lautan. Institut Pertanian Bogor. Bogor

Bengen 2000. Mangrove surga yang terkoyak. Trubus 31.
Bengen D. G 1999. Pedoman Teknis Pengenalan dan Pengelolaan Ekonomi Mangrove. Pusat Kajian Sumberdaya Pesisir dan Lautan. Institut Pertanian Bogor. Bogor

Duke, N. 1996. Mangrove reforestation in Panama: an evaluation of planting areas deforested by a large oil spill. In: Field C. (ed.) Restoration of Mangrove Ecosystems. Okinawa: International Tropical Timber Organization and International Society for Mangrove Ecosystems.

FAO. 2003. Mangrove: distribution and extent.

http://www.fao.org/forestry/ site/3642/en/

Kusmana C. 2009. Pengelolaan Ekosistem mangrove secara terpadu. Diakses dari: http//cecep_kusmana.staff.ipb.ac.i d/ files/2011/ 01/ 2009Pengelolaan-Sistemmangrovesecara-terpadu.pdf [10] Kusmana et al 2005. Teknik Rehabilitasi Mangrove. Fakultas Kehutanan Institut Pertanian Bogor. Bogor.

Ningsih, S.S 2008. Inventarisasi Mangrove sebagai bagian dari upaya pengelolaan wilayah pesisir di kabupaten Deli Serdang. Tesis Sekolah Pascasarjana Universitas Sumatera Utara. Medan.

Primack, R.B., J. Supriatna, M. Indrawan\& P.Kramadibrata. 1998. Biologi Konservasi. Yayasan Obor. Jakarta

Rahim. 2016. Struktur dan Komposisi mangrove dan Upaya pengelolaan wilayah pesisir di kecamatan 


\section{Bengalon Kabupaten Kutai Timur. Tesis Program Pascasarjana Universitas Mulawarman. Samarinda.}

Setyawan, A.D., Kusumo. W., Purin, C.P. 2004. Ekosistem mangrove di Jawa:2. Restorasi. Biodiversitas 5(2):105-118.

Soemartono, 2002. Kontribusi perguruan tinggi dalam rehabilitasi dan pengembangan hutan mangrove. Prosiding Workshop Rehabilitasi Mangrove Tingkat Nasional. Yogyakarta. 2002

Soemodihardjo, S., R. Ongkosono, \& A. Abdullah. 1986. Diskusi Panel Daya guna dan Batas Lebar Jalur Hijau Hutan Mangrove. Panitian Program MAB Indonesia - LIPI. Proyek Penelitian Lingkungan Hidup. P17 - 22.
Soerianegara 1987. Makalah penentuan batas Lebar Jalur Hijau Hutan Mangrove. Prosiding Seminar III Hutan Mangrove. Proyek Penelitian Lingkungan Hidup LIPI. Jakarta.

Soemodihardjo, Ongkosono, dan Abdullah 1986.

Simarangkir. $\quad$ B.D.A.S. 2012. Pembangunan Hutan Tanaman Tropis Lestari. Kanisius. Yogyakarta.

Tom linson PB. 1986. The Botany of Mangroves. Cambridge University Press.Cambridge.

Undang-undang Nomor 41 tahun 1999. Tentang Kehutanan

Undang-Undang Nomor 19 tahun 2004 